\title{
Review Article \\ Transfusion Strategy: Impact of Haemodynamics and the Challenge of Haemodilution
}

\author{
Carl-Johan Jakobsen \\ Department of Anaesthesiology and Intensive Care, Aarhus University Hospital, 8200 Aarhus N, Denmark \\ Correspondence should be addressed to Carl-Johan Jakobsen; cjj@dadlnet.dk
}

Received 18 June 2014; Accepted 17 July 2014; Published 6 August 2014

Academic Editor: Erwin Strasser

Copyright (C) 2014 Carl-Johan Jakobsen. This is an open access article distributed under the Creative Commons Attribution License, which permits unrestricted use, distribution, and reproduction in any medium, provided the original work is properly cited.

\begin{abstract}
Blood transfusion is associated with increased morbidity and mortality and numerous reports have emphasised the need for reduction. Following this there is increased attention to the concept of patient blood management. However, bleeding is relatively common following cardiac surgery and is further enhanced by the continued antiplatelet therapy policy. Another important issue is that cardiopulmonary bypass leads to haemodilution and a potential blood loss. The basic role of blood is oxygen transport to the organs. The determining factors of oxygen delivery are cardiac output, haemoglobin, and saturation. If oxygen delivery/consumption is out of balance, the compensation mechanisms are simple, as a decrease in one factor results in an increase in one or two other factors. Patients with coexisting cardiac diseases may be of particular risk, but studies indicate that patients with coexisting cardiac diseases tolerate moderate anaemia and may even benefit from a restrictive transfusion regimen. Further it has been shown that patients with reduced left ventricular function are able to compensate with increased cardiac output in response to bleeding and haemodilution if normovolaemia is maintained. In conclusion the evidence supports that each institution establishes its own patient blood management strategy to both conserve blood products and maximise outcome.
\end{abstract}

\section{Status in Frequency of Transfusion and Impact on Outcome in Cardiac Surgery}

The concept of patient blood management is gaining increased attention. During the last decade numerous reports have emphasised the need for reductions in transfusions of blood and blood products as allogeneic red blood cell (RBC) transfusions are associated with increased morbidity and mortality [1-10], increased risk of severe postoperative infections [5], adverse effects or risk of transferring pathogens $[11,12]$, relatively high costs, and shortage of blood bank products $[6,12-14]$. Postoperative severe bleeding is relatively common following cardiac surgery compared to other surgical specialties and is considered a serious complication associated with increased morbidity and mortality [1421]. Within the cardiac surgery population, patients with advanced age and long cardiopulmonary bypass (CPB) are especially at risk of postoperative bleeding $[18,19]$. Moreover, it is well known that excessive bleeding may be caused by surgical factors and impaired haemostasis due to enhanced fibrinolysis, platelet dysfunction, haemodilution, acidosis, hypothermia, and consumption of coagulation factors as well as the surgical trauma alone $[22,23]$.

During recent years several cardiac surgery studies have reported on the long term mortality after transfusion with blood and blood products [6-10]. Although not all [7], the majority of studies report a higher long term mortality after blood transfusion $[6,9,10,24]$ (Figure 1). However, the reports are mainly from designated types of surgery [7-9] or single centre studies $[6,8,9]$. In some studies the KaplanMeyer plots tend to run parallel after the first month when including the immediate postoperative mortality, indicating less impact on the long term survival $[6,9,10]$.

One of the last published evidence based guidelines for the transfusion of RBC concluded that "red blood cell transfusions should not be dictated by a single haemoglobin $\mathrm{Hb})$ "transfusion trigger", but instead should be based on the patient's risk of developing complications of inadequate oxygenation." Furthermore, that RBC transfusion would generally be indicated, but not mandatory, at $\mathrm{Hb}$ levels lower than $6.0 \mathrm{~g} / \mathrm{dL}(3.7 \mathrm{mmol} / \mathrm{L})$ and rarely indicated in patients with haemoglobin higher than $10.0 \mathrm{~g} / \mathrm{dL}(6.1 \mathrm{mmol} / \mathrm{L})$ [25]. In 


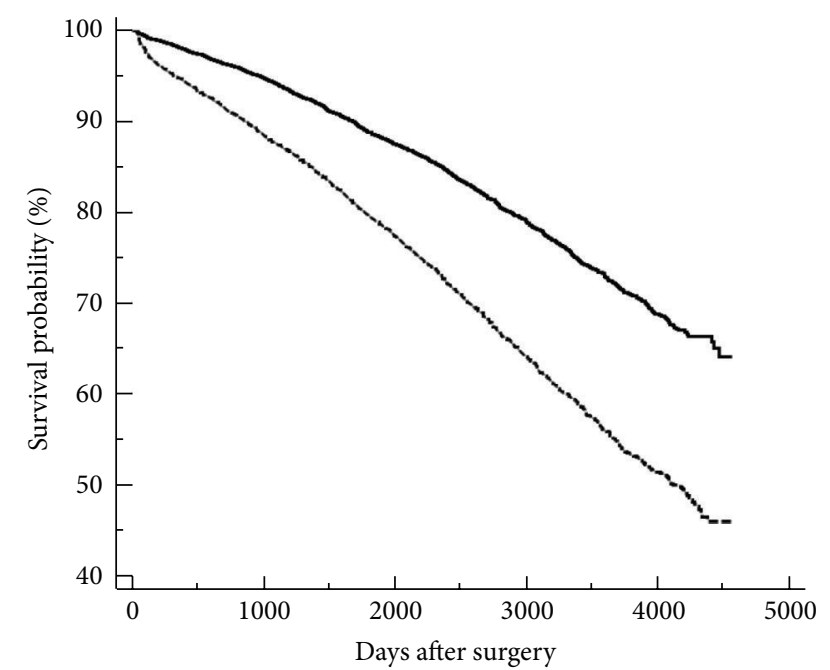

- None

- - $\mathrm{RBC}$ transfusion

FIGURE 1: Unadjusted long term survival following standard cardiac surgery procedures (CABG, AVR, and MVR) divided on perioperative blood transfusion [24]. Patients dying within first 30 days postoperatively were excluded from analysis.

many types of major surgery these recommendations have been followed and the use of transfusions reduced. However, in cardiac and vascular surgery the use of blood and blood products is still common clinical practice.

From a survey of cardiac procedures covering monitoring, anaesthesia and transfusions carried out in 2005, it was found that almost $40 \%$ of European institutions used blood or blood products in more than half of their cardiac surgery patients [26]. When calculating the number of surgical procedures in each institution and number of patients not receiving blood or blood products, $55.7 \%$ of European cardiac surgery patients received blood or blood products in the perioperative period. However, the difference in transfusions from less than $10 \%$ of patients to $100 \%$ that do receive blood or blood product transfusion (Figure 2) is interesting and indicates that transfusions are guided by local policies and not evidence based practice.

\section{Continued Antiplatelet Therapy}

Patients referred for coronary artery bypass graft (CABG) are more commonly treated with antiplatelet agents especially aspirin and oral adenosine diphosphate (ADP) receptor antagonists together with newer alternative low molecular heparin drugs, like fondaparinux. Long term aspirin therapy is the standard of care in patients with coronary artery disease, while concomitant treatment with oral ADP receptor antagonists is recommended for patients with recent acute coronary syndrome (ACS) or percutaneous coronary intervention (PCI) [27-29]. Studies do not agree on the impact of these drugs on perioperative bleeding. Studies have found both reduced mortality and no difference in bleeding [30] or no difference in bleeding complications in patients treated

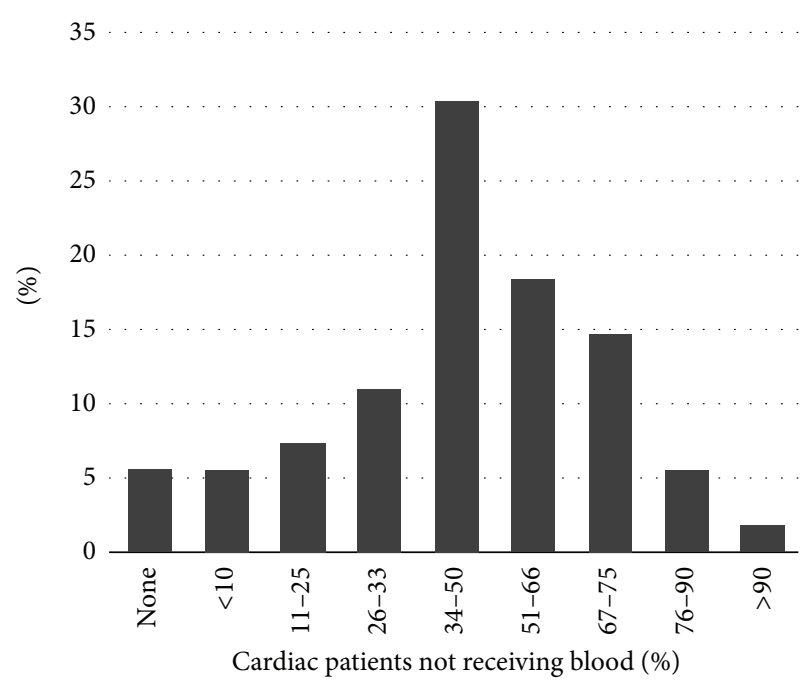

FIGURE 2: The fraction of patient not receiving perioperative blood transfusion in European cardiac centers (survey from 2005: 119 European institutions covering 117,800 cardiac procedures).

with antiplatelet drugs $[31,32]$. This is in contrast to other studies reporting higher transfusion requirements without effect on mortality [33] or increased bleeding and transfusion as well as increased risk of myocardial infarction [34].

In the CRUSADE study following established guidelines a significant increase in transfusion requirements in patients continuing on clopidogrel was observed compared to patients where the drug was discontinued more than five days before surgery [35]. Similarly, large cohort studies found significant increases in major bleeding and reoperation rates in clopidogrel-exposed CABG patients $[33,36]$.

The use of antiplatelet agents at the time of CABG carries both benefits and risks. The drugs are effective in reducing ischemic events in high-risk patients awaiting surgery. After surgery drugs may prevent graft occlusion and recurrence of ischemic episodes. However, antiplatelet drugs also aggravate perioperative bleeding followed by increased perioperative blood loss, increased transfusion requirements, and hemodynamic instability $[35,37,38]$. As the indications for oral antiplatelet drugs expand, cardiac surgeons frequently have to make decision about the timing of surgery in patients exposed to these drugs. Current international guidelines recommend discontinuing aspirin two to ten days before elective cardiac surgery, while the ADP receptor antagonist clopidogrel should be withdrawn at least five days before elective CABG $[39,40]$.

\section{Circulation and Red Blood Cells (Haemoglobin)}

3.1. Haemoglobin and Organ Oxygenation. The basic role of blood is to transport and deliver oxygen to the organs to maintain organ function. The determining factors and variables influencing organ oxygenation are shown in Figure 3. It is evident that clinical and some hemodynamic measurements are imperative to gain the required information 


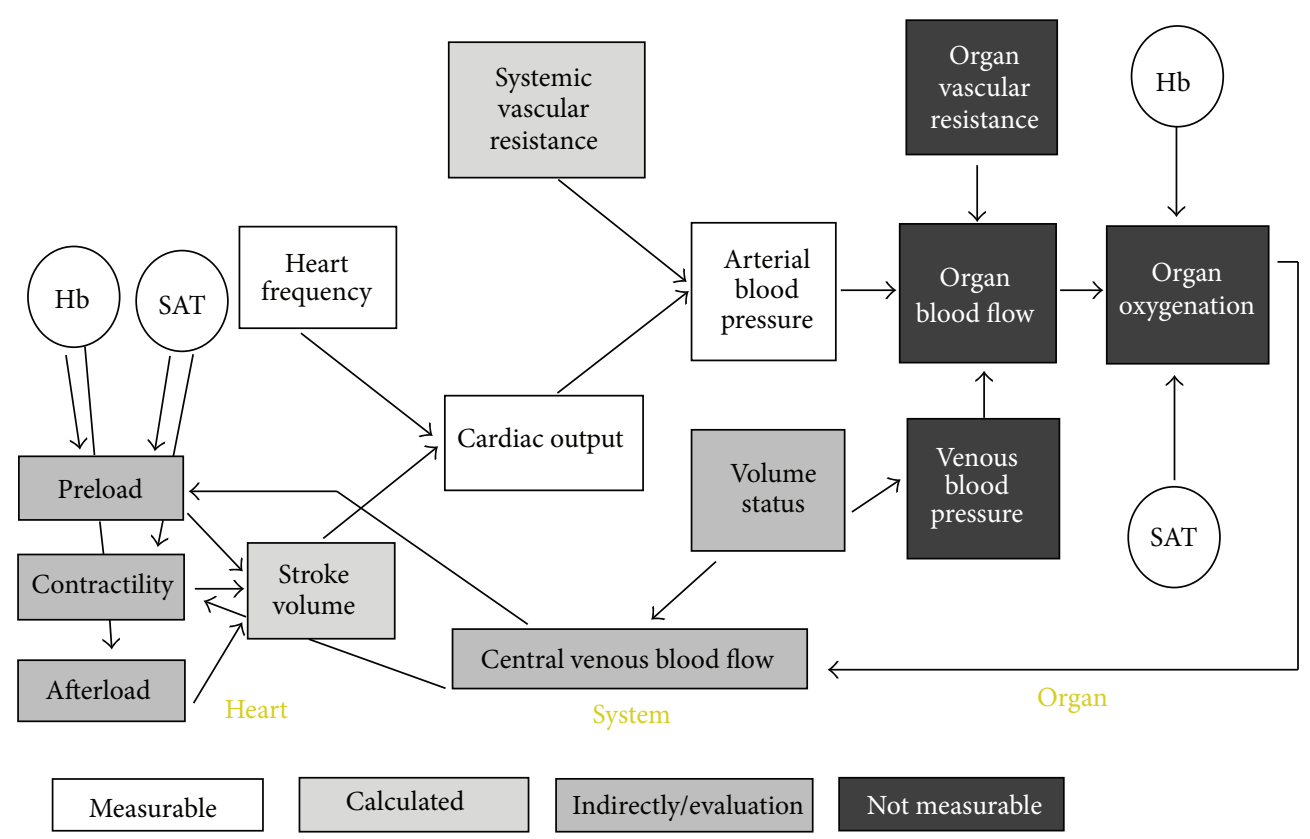

FIGURE 3: Variables and factors influencing and determining organ oxygenation and the measurement possibilities.

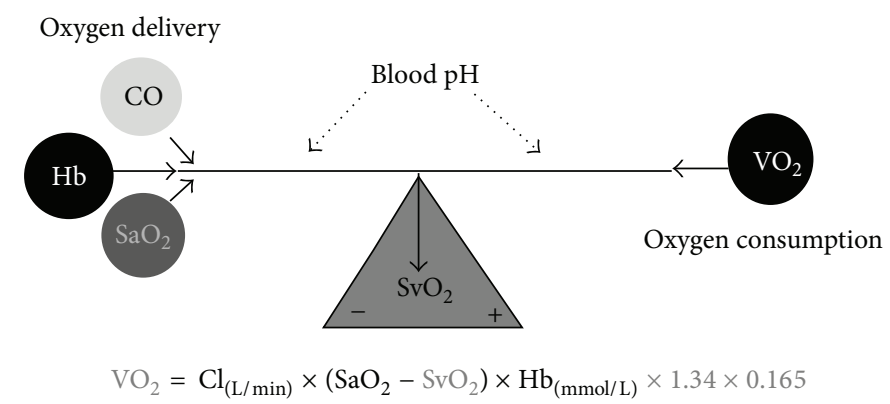

FIGURE 4: Factor and relations between the oxygen delivery and oxygen consumption.

for decision making. The question is how comprehensive monitoring should be in order to fulfill these needs. Even with the most extensive invasive haemodynamic monitoring the obtained information is not fully adequate, as individual organ monitoring is not possible or available in clinical practice. We do have some intervention possibilities for blood pressure, heart rate, haemoglobin level, and volume status and it is possible to operate influence factors such as oxygen saturation, vascular resistance, preload, and cardiac output, while organ blood flow and organ oxygenation are difficult to influence directly.

3.2. Circulation, Oxygen Consumption, and Haemoglobin. The correlation between blood flow, oxygen delivery, and consumption together with haemoglobin can easily be visualised (Figure 4). The figure demonstrates that oxygen delivery in principle is determined by only three variables, cardiac output $(\mathrm{CO})$, haemoglobin $(\mathrm{Hb})$ level, and oxygenation $\left(\mathrm{SaO}_{2}\right)$. Additionally, blood $\mathrm{pH}$ value influences the binding of oxygen to haemoglobin.
If oxygen delivery is out of balance with oxygen consumption, the compensation mechanisms are relatively simple, as a decrease in haemoglobin must result in a compensatory increase in either cardiac index or oxygen extraction or a combination. Furthermore, the relation is independent of the fact that CO changes with age [41] and that the ratio of CO to total blood volume changes from roughly $3: 1$ in small children to $2: 3$ or lower in the elderly cardiac patient.

A valuable parameter in evaluating need for inotropic support or RBC transfusion is whether oxygen consumption is adequately covered by oxygen delivery. In general, oxygen delivery to the cells is higher than actual consumption. When oxygen consumption is high (i.e., during exercise) the increased oxygen requirement is usually provided by an increased cardiac output. However, low cardiac output, low haemoglobin concentration (anaemia), or low haemoglobin $\mathrm{O}_{2}$ saturation will result in an inadequate delivery of oxygen, unless a compensatory change occurs in one of the other factors. Alternatively, if oxygen delivery falls relative to oxygen consumption, the tissues extract more oxygen from the haemoglobin and the saturation of mixed venous blood 


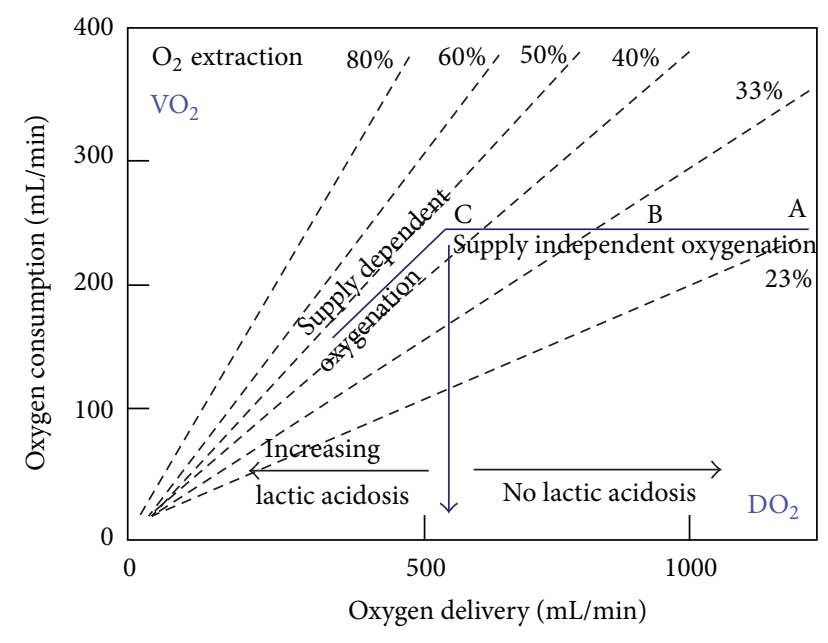

FIGURE 5: Oxygen consumption dependency of oxygen supply and influence of oxygen extraction fraction.

$\left(\mathrm{SvO}_{2}\right)$ falls below 70\% (A-B in Figure 5). A reduction below point " $\mathrm{C}$ " in Figure 4 cannot be compensated by an increased oxygen extraction and results in anaerobic metabolism and lactic acidosis, and oxygen consumption becomes totally dependent on oxygen supply.

Oxygen is carried in the blood in two forms: primarily by haemoglobin but a very small amount is dissolved in the plasma. When fully oxygen saturated $\left(\mathrm{PO}_{2}>13.3 \mathrm{kPa}\right)$ only $3 \mathrm{~mL}$ of oxygen will be dissolved in every litre of plasma. If the $\mathrm{PO}_{2}$ of oxygen in arterial blood $\left(\mathrm{PaO}_{2}\right)$ is increased significantly (breathing 100\% oxygen), a small amount of extra oxygen will dissolve in the plasma at a rate of $0.023 \mathrm{~mL}$ $\mathrm{O}_{2} / 100 \mathrm{~mL}$ blood $/ \mathrm{kPa} \mathrm{PO}_{2}$. Normally, there will be no significant increase in the amount carried by haemoglobin if oxygen saturation is already higher than $95 \%$.

In the literature there is some indications that patients with coexisting cardiac diseases may have a particular risk of developing impaired oxygenation at lower haemoglobin levels, but the documentation for this is not that convincing. In patients undergoing cardiac surgery the relation between transfusion and postoperative morbidity and mortality is more uncertain. Studies of cardiac surgery patients have shown increased mortality after RBC transfusions [42, 43]. Further, others have found that lowering of the $\mathrm{Hb}$ threshold for transfusion in patients undergoing coronary artery bypass surgery (CABG) from 9 to $8 \mathrm{~g} / \mathrm{dL}$ (5.5 to $5.0 \mathrm{mmol} / \mathrm{L}$ ) was neither followed by a higher mortality nor followed by an increase in adverse effects by accepting the lower postoperative haemoglobin [44]. This indicates that patients with coexisting cardiac diseases, including coronary artery disease (CAD), tolerate moderate anaemia. Another study showed that patients may even benefit from a restrictive transfusion regimen followed by a lower morbidity and mortality [2]. The mean haemoglobin at transfusion in this study was $8.4 \mathrm{~g} / \mathrm{dL}$ $(5.1 \mathrm{mmol} / \mathrm{L})$ and both ICU and overall mortality rate were higher in transfused patients. This was confirmed in multivariate analyses and a matched pair analysis [2]. The findings were further supported in an ICU study where patients with
TABLE 1: The relation between EuroSCORE (minus age factor) and age score related to the percentage of patients receiving blood transfusions among 10,889 patients from 1999 to 2010 at Aarhus University Hospital.

\begin{tabular}{lccccc}
\hline \multicolumn{3}{c}{ EuroSCORE (minus age score) } & \multicolumn{3}{c}{ Age score } \\
Score & Number & Blood \% & Age & Number & Blood \% \\
\hline $0-1$ & 3302 & 23.5 & $<60$ & 3002 & 28.2 \\
$2-3$ & 5444 & 32.3 & $60-64$ & 1554 & 32.1 \\
$4-5$ & 2977 & 42.0 & $65-69$ & 1887 & 39.3 \\
$6-7$ & 1338 & 48.8 & $70-74$ & 1996 & 39.8 \\
$8-9$ & 744 & 58.6 & $75-79$ & 1649 & 45.2 \\
$10-11$ & 575 & 66.7 & $80-84$ & 646 & 47.5 \\
$>11$ & 516 & 77.9 & $>84$ & 155 & 47.7 \\
\hline
\end{tabular}

known cardiovascular disease had equal level of mortality and less organ dysfunction if in a transfusion restrictive group [45].

In contrast, one study indicated that RBC transfusions may decrease mortality in elderly patients with acute myocardial infarction and an admission haematocrit below 30\% [46]. Another study shows increased in-hospital mortality in patients with lower preoperative haemoglobin levels [47]. However, the first study is not without methodological challenges and needs careful analysis as patients with normal haemoglobin levels seemed to be treated more intensely. Previously, we have demonstrated a correlation between preoperative haematocrit (Hct) and 30-day mortality [26]. However, when compensated for EuroSCORE [48-50] the 30-day mortality was independent of haemoglobin level and only correlated with the EuroSCORE. The data showed a strong relationship between actual $\mathrm{RBC}$ transfusion and residual EuroSCORE (EuroSCORE minus age factor) and interestingly also the lack of correlation between age higher than 74 years and RBC transfusion (Table 1).

The first priority of perioperative fluid therapy in surgical patients is to achieve optimal filling of the heart with crystalloids and colloids to optimise cardiovascular function, decrease postoperative morbidity, and shorten the length of hospitalisation $[51,52]$. In cardiac surgery patients and many intensive care patients with $\mathrm{PaO}_{2}>95 \%$, optimisation of arterial saturation only adds little to oxygen delivery, leaving only increasing $\mathrm{CO}$ or $\mathrm{Hb}$ as possible means to increase oxygen delivery. Infusion of colloids reduces the $\mathrm{Hb}$ level and thus, despite unchanged total haemoglobin content, oxygen delivery in theory. However, the impact on CO normally compensates for that and in hypovolaemic patients especially the overall impact may be substantially higher $\mathrm{CO}$ and thus oxygen delivery. Following infusion of RBC in this type of patients may have a double effect on oxygen delivery as both $\mathrm{Hb}$ and $\mathrm{CO}$ are increased. In contrast, in severely overloaded patients where further compensation in cardiac output is compromised or even deteriorated after infusion of colloid or $\mathrm{RBC}$, there might be no effect on the oxygen delivery. In these cases inotropic support may be the only way to increase oxygen delivery. 


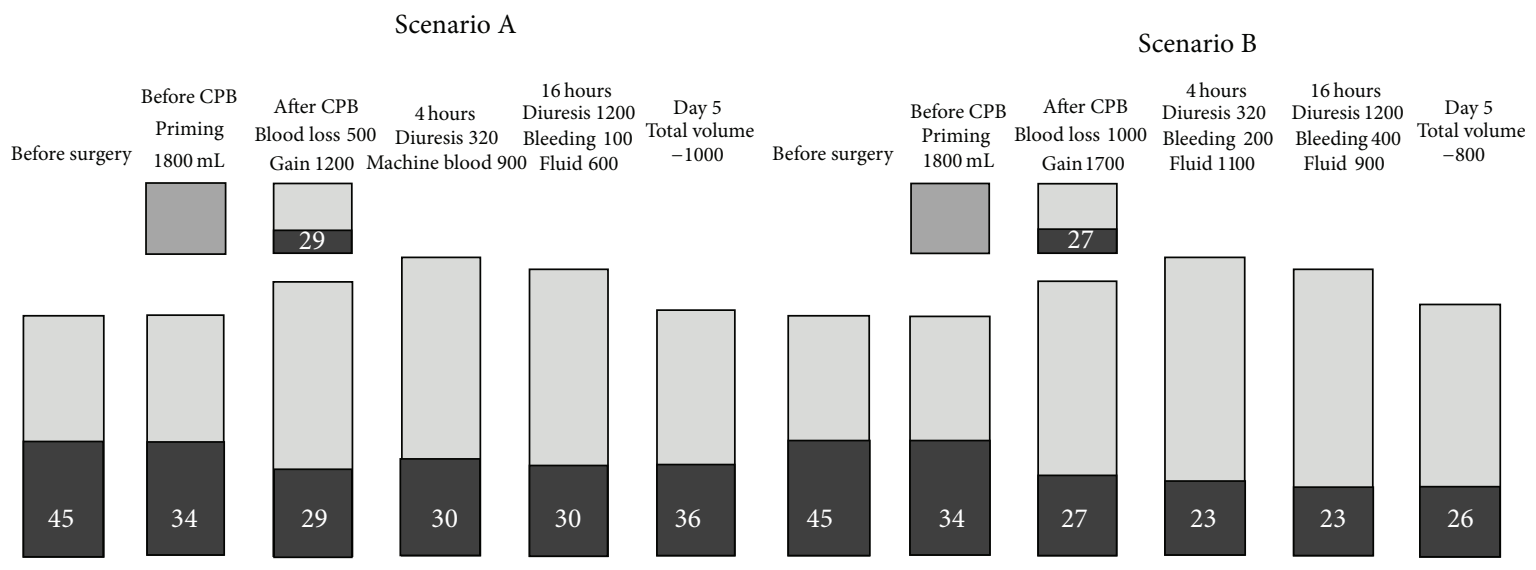

FIGURE 6: Perioperative changes in haematocrit and total haemoglobin. SCENARIO A: optimal perioperative management; impact of accurate blood conservation, use of cell-saver/retransfusion of machine blood and autotransfusion. SCENARIO B: nonoptimal perioperative handling; no use of cell-saver/retransfusion of machine blood and postoperative autotransfusion.

Many cardiac or critically ill patients are not monitored with pulmonary artery catheters and hence information of $\mathrm{CO}$ and $\mathrm{SvO}_{2}$ is not available. Central venous oxygen saturation $\left(\mathrm{ScvO}_{2}\right)$ obtained from the superior vena cava has been proposed as a surrogate for $\mathrm{SvO}_{2}$ and may reflect the balance between oxygen supply and demand. Studies have shown that the difference between $\mathrm{ScvO}_{2}$ and $\mathrm{SvO}_{2}$ is consistently about $5 \%$ across a wide range of cardiorespiratory conditions in both animals and humans $[53,54]$. However, $\mathrm{ScvO}_{2}$ obtained from a central venous catheter is not fully interchangeable with mixed $\mathrm{SvO}_{2}$, but it can give some indication of oxygen balance in patients with peripheral saturation, $\mathrm{CO}$ and $\mathrm{Hct}$ within normal limits [55].

3.3. The Haemodilution Challenge. One of the principal differences in cardiac surgery compared to other types of major surgery is the use of cardiopulmonary bypass (CPB). This leads to a $20-30 \%$ haemodilution and when weaning from $\mathrm{CPB}$ a relatively big portion of red blood cells (RBC) are left in the heart lung machine (HLM) (Figure 6). Although the surgeon is very careful during the procedure, a smaller portion of blood is always lost. Using either cell-saver or retransfusing of suctioned blood will, however, limit the total loss. If using autotransfusion in the postoperative phase the perioperative blood loss during cardiac surgery can be diminished to approximately one unit of RBC (SCENARIO A) and there is thus no need for transfusion. However, if none of these procedures are used, the overall result will be a considerable blood loss and a low postoperative haematocrit level (SCENARIO B). Consequently, the patient will inevitably receive $1-3$ units of $\mathrm{RBC}$. If the patient continuously has problems with bleeding or haemodynamic instability, the risk of adding plasma or platelets is reasonably high.

Some studies have found low haemoglobin levels during $\mathrm{CPB}$ to be associated with increased postoperative morbidity and mortality $[56,57]$ while other studies have not been able to find such a correlation $[43,58]$.

Patients with coronary artery disease (CAD) may have an increased risk of myocardial ischemia in combination with
TABLE 2: Transfusion of blood or blood products related to cardiac surgery.

\begin{tabular}{lcc}
\hline Procedure type & Number & Transfusion \% \\
\hline CABG & 5695 & 38.9 \\
Single valve & 2373 & 39.2 \\
CABG plus valve & 1152 & 52.1 \\
Single other procedure & 760 & 45.4 \\
Double procedures & 472 & 55.1 \\
Aortic surgery & 437 & 64.5 \\
\hline All & 10889 & 42.6 \\
\hline
\end{tabular}

low haemoglobin levels. However, experimental and clinical data indicate that persons with CAD tolerate moderate normovolaemic haemodilution well [59-62]. Interestingly, data from our database show that patients with CABG received less blood and blood products (Table 2).

Regional changes in myocardial systolic and diastolic contractile dysfunction $[63,64]$ and ECG signs of myocardial ischemia [65-68] may develop in areas supplied by a compromised coronary artery at low haemoglobin levels. Additionally, haemoglobin levels below $6.0 \mathrm{~g} / \mathrm{dL}(3.7 \mathrm{mmol} / \mathrm{L})$ have been associated with increased postoperative mortality in patients with coexisting cardiovascular disease, including CAD [69].

During both haemodilution [59] and blood transfusion [70] patients with a left ventricular ejection fraction between $25 \%$ and $85 \%$ responded similarly. This indicates that also patients with a reduced left ventricular ejection fraction are able to compensate with increased cardiac output in response to haemodilution if normovolaemia is maintained. However, the number of patients with low ejection fractions was limited and the findings should not necessarily be extrapolated to the low range of patients with left ventricular ejection fraction.

Patients above 65 years without known cardiac disease tolerated haemodilution to a haemoglobin of $8.8 \mathrm{~g} / \mathrm{dL}$ $(5.4 \mathrm{mmol} / \mathrm{L})$ well [71]. Beta-blocked CAD patients between 35 and 81 years responded adequately during haemodilution 
with an increase in cardiac output and oxygen extraction [59]. Similarly, during blood transfusion the compensatory changes in cardiac output, oxygen delivery, and oxygen consumption seemed to be independent of age (32 to 81 years) [70]. However, this study had relatively few patients above 75 years, stressing that these findings may not apply to the very old patients.

Patients with significant mitral insufficiency, including those with atrial fibrillation, tolerate moderate haemodilution to a haemoglobin level of $10 \mathrm{~g} / \mathrm{dL}(6.1 \mathrm{mmol} / \mathrm{L})$ [72]. Tolerance of acute haemodilution or anaemia in patients with other valve abnormalities is less well known. Theoretically, patients with aortic and pulmonary stenosis may be less tolerant to haemodilution as the increase in cardiac output during haemodilution may be limited due to the valvular stenosis. A more liberal transfusion regimen thus appears indicated in such patients. However, in the postoperative phase these patients may most likely be treated as patients without coexisting cardiovascular diseases.

In patients with coexisting cardiovascular diseases refusing RBC transfusions for religious reasons, postoperative haemoglobin levels below $6.0 \mathrm{~g} / \mathrm{dL}(3.7 \mathrm{mmol} / \mathrm{L})$ were associated with increased mortality and morbidity and an increasingly greater difference in mortality and morbidity between patients with and without coexisting cardiovascular diseases [69].

In order to avoid or minimize transfusions in patients with low haemoglobin it should be considered whether preoperative haemoglobin adjustment is needed. However, this is not possible in acute or life threatening situations. In this evaluation it is evident that the $20-30 \%$ haemodilution during CPB might be the primary concern if the patient does not have cardiac capacity to tolerate very low post-CPB haemoglobin or that a needed high HTLM cardiac output during $\mathrm{CPB}$ may increase perioperative complications. The overall conclusion is that even patients with coexisting cardiac diseases tolerate moderate haemodilution or acute anaemia well if normovolaemia is maintained. However, an excessive and aggressive haemodilution may cause myocardial ischemia which is reversible with a blood transfusion, even in normovolaemic patients $[64,68,73]$, and the lowest acceptable haemoglobin in patients with coexisting cardiovascular diseases is approximately $6.0 \mathrm{~g} / \mathrm{dL}(3.7 \mathrm{mmol} / \mathrm{L}$, haematocrit 0.18-0.20) [69]. Patients where pre-CPB calculations indicate a lower level during or right after CPB might be the target for preoperative haemoglobin adjustment with erythropoietin with or without autologous blood transfusion.

3.4. Haemodynamic Effect of Relative Anaemia. The haemoglobin level at which regional cardiac ischemia may occur varies considerably and depends on both the degree of coronary stenosis [74] and whether it is a single- or a multivessel CAD [75]. Patients with or at risk of CAD should thus not automatically receive a transfusion at a specific haemoglobin level but only if oxygenation is inadequate as suggested by the American Society of Anaesthesiologists (ASA) [12]. The question is whether anaemia-related myocardial ischemia is reversible by blood transfusion, which seems to be the case in some experimental [64] and clinical $[68,73]$ settings.

Patients with progressively lower haemoglobin levels also have other risk factors such as diabetes, preoperative congestive heart failure, prior coronary artery bypass operation, low left ventricular ejection fraction, and a higher frequency of emergency surgery [56]. A high correlation has been found between such risk factors and a low haemoglobin level [58] and the independent contribution of a low perioperative haemoglobin level to mortality is difficult to assess. After adjusting for other risk factors, only a haematocrit below or equal to $14 \%$ during $\mathrm{CPB}$ remained an independent predictor for increased mortality [57].

Only a prospective randomised study design can definitively determine whether varying haemoglobin transfusion triggers affect morbidity and mortality. In a study of ICU patients it was demonstrated that a haemoglobin transfusion trigger of $7 \mathrm{~g} / \mathrm{dL}(4.3 \mathrm{mmol} / \mathrm{L})$ did not negatively impact on mortality and morbidity, neither in general ICU patients nor in patients with coexisting cardiac diseases $[1,45]$.

Several studies have shown the importance of controlling haemodynamics during cardiac $[76,77]$ as well as noncardiac surgery [78]. Haemodynamic management is generally less strict postoperatively compared with intraoperatively. Therefore, episodes of tachycardia may occur, which may be associated with ST-segment depression, in particular in patients with $t$ low haemoglobin levels [67]. Treating tachycardia alleviates ST-segment depression [68] and thus postoperative heart rate control. Preventing tachycardia and following STsegment depression is thus imperative [79] in patients with or at risk of CAD. In addition, postoperative oxygenation is generally lower than during peroperative mechanical ventilation with a high inspiratory oxygen concentration. Therefore, higher postoperative haemoglobin levels of 7 to $8 \mathrm{~g} / \mathrm{dL}$ (4.3$4.9 \mathrm{mmol} / \mathrm{L}$ ) may be justified in patients with coexisting cardiac diseases.

The question of when transfusion is appropriate in a patient with a coexisting cardiac disease thus remains unanswered. At a haemoglobin level lower than $6.0 \mathrm{~g} / \mathrm{dL}$ $(3.7 \mathrm{mmol} / \mathrm{L})$ blood transfusions may be indicated in most patients and in particular in patients with coexisting cardiac diseases $[25,69,80,81]$. Furthermore, it has been shown in cardiac surgery patients that oxygen consumption only increased following a blood transfusion when oxygen consumption was very low before blood transfusion [70]. As this remains impossible to determine also in patients with coexisting cardiac diseases, the haemoglobin level, at which a transfusion would generally be indicated, should follow the guidelines from the ASA, stating that "red blood cell transfusions should be based on the patient's risk of developing complications of inadequate oxygenation" [25]. The immediate question is then, what are the signs of a beginning inadequate oxygenation in patients with coexisting cardiac diseases? Inadequate oxygenation may become globally manifested in the form of general haemodynamic instability with a tendency to hypotension and tachycardia despite normovolaemia, oxygen extraction higher than 50\% [80-82], or myocardial ischemia detected by continuous 5-lead ECG monitoring, ideally with automatic ST-segment analysis 
$[65,68,83]$ and by new wall motion abnormalities in transoesophageal echocardiography [84]. ST-segment depressions above $0.1 \mathrm{mV}$ or new ST-segment elevations above $0.2 \mathrm{mV}$ during more than one minute generally are regarded as a marker of myocardial ischemia. During progressive haemodilution, primarily ST-segment depression is observed [68], suggesting subendocardial ischaemia. Such anaemia-related ischaemia may, in case of tachycardia, be reversed by decreasing the heart rate [68] and by increasing the haemoglobin level 1-2 $\mathrm{g} / \mathrm{dL}(0.6-1.2 \mathrm{mmol} / \mathrm{L})$ by transfusion [64]. New wall motion abnormalities clinically detected by transoesophageal echocardiography may be the result of myocardial ischemia and can be treated by a minor increase in haemoglobin of 1 to $2 \mathrm{~g} / \mathrm{dL}(0.6-1.2 \mathrm{mmol} / \mathrm{L})$ [64].

Early signs of inadequate circulation are general haemodynamic instability characterised by relative tachycardia and hypotension $[81,85]$ together with an oxygen extraction fraction above $50 \%$, a low mixed venous oxygen partial pressure $\left(\mathrm{PvO}_{2}\right)$, and a decrease in oxygen consumption [80, 81]. An oxygen extraction higher than $50 \%$ has been found to indicate exhaustion of compensatory mechanisms in several studies [86-89] and might thus represent a transfusion indication. Oxygen consumption decreases very late and at very low haemoglobin levels during progressive normovolaemic haemodilution $[89,90]$ in conditions where oxygen extraction has increased and $\mathrm{PvO}_{2}$ has already decreased [88]. Therefore, any decrease in oxygen consumption of more than $10 \%$ at low haemoglobin levels [71] should be viewed as a potential sign of a compromised oxygenation and a blood transfusion should be considered if normovolaemia has been achieved. In patients with coexisting cardiac diseases, the principles of RBC transfusion are not considerably different from healthy patients and must also largely be based on early signs of impaired oxygenation of specific organs or the entire organism. Impaired oxygenation may be reached at higher haemoglobin values than in healthy patients and most patients have considerable variations in haemodynamic values.

A previous study found considerable interpatient differences and intrapatient variation in patients monitored the night before cardiac surgery (Figure 7) [91]. The most pronounced intrapatient variation was found in the cardiac index, ranging from 1.9 to $5.3 \mathrm{l} / \mathrm{min} / \mathrm{m}^{2}$. Most of the patients had periodic $\mathrm{SpO}_{2}$ values $\leq 92$ and half of them in more than $15 \%$ of the observations. Overall a $\mathrm{SvO}_{2}<70 \%$ was found in more than $40 \%$ of observations and less than $64 \%$ in more than $20 \%$ of the observations together with drops below $50 \%$ without obvious reasons. Although the number of patients in the study was low the conclusion was that intrapatient variation was unexpectedly high in most hemodynamic variables. This demonstrated the challenge in using hemodynamic parameters to guide treatment and indicated that goal oriented therapy using currently accepted values may result in overtreatment in some patients [91].

\section{The Function of Stored Red Blood Cells}

A restrictive $\mathrm{RBC}$ transfusion policy has proven equally effective and possibly even superior to a more liberal transfusion

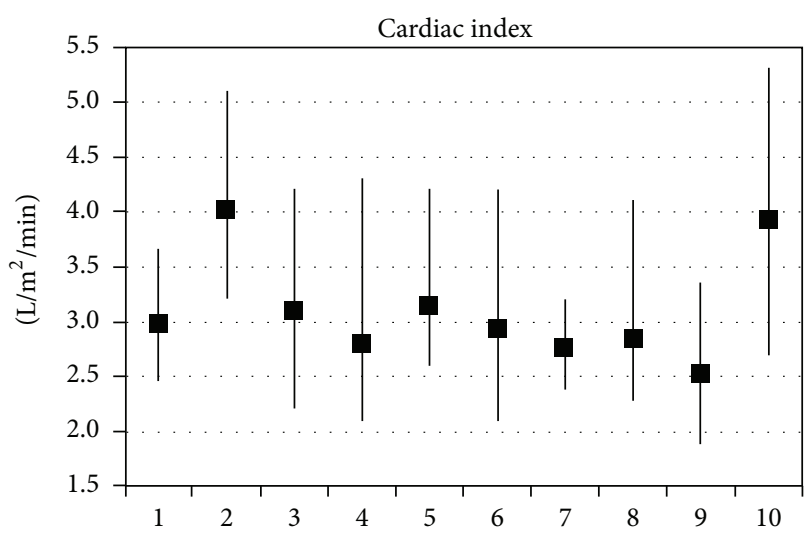

(a)

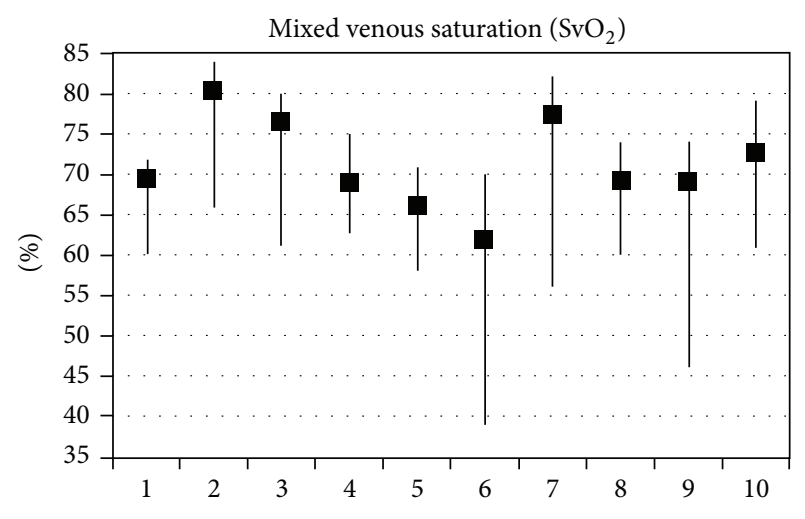

(b)

FIGURE 7: Variances in cardiac index and $\mathrm{SvO}_{2}$ in elective patients the night before surgery [91].

strategy [1]. Although there currently is no clear explanation for this effect, infections [92], immunosuppression [3], and the age of the RBC at the time of transfusion $[5,93,94]$ have been suggested as possible impact factors.

Storage lesions are morphological and biochemical alterations found after RBC storage [95]. The clinical consequence of the storage lesions is a reduced survival time of red blood cells after the transfusion. Whether stored RBC is also compromised in transporting oxygen to tissue is still controversial. Several clinical $[93,96,97]$ and experimental animal studies $[98,99]$ support the notion that RBC older than 3 weeks have a reduced ability to transport oxygen to the tissues. Animal studies have found a malperfused and underoxygenated microvasculature after haemodilution [100] and a $26 \%$ decrease in micro vascular oxygen concentration after transfusion with washed human RBCs in haemodiluted rats [101]. In human a recent study has shown increased risk of severe postoperative infections after cardiac surgery associated with the use of old RBC [5].

However, the findings are not uniform as a recent clinical study could not demonstrate an effect of stored blood on oxygenation parameters [102] and another did not observe an increase in morbidity in coronary artery bypass graft surgery patients receiving old RBCs [14] or could not find 
a correlation between median ages of the $\mathrm{RBC}$ units and clinical outcomes [103].

These differences in study outcomes may be explained by the inherent difficulty to measure tissue oxygen concentrations in the clinical setting. To estimate the effect of RBC transfusion on tissue oxygenation in patients, indirect measuring techniques have been used as surrogate endpoints. In addition, the diversity in the design of the performed studies complicates a proper comparison of their results. There seems to be an agreement that when a substantial part of the units issued for transfusion is stored for more than 3 weeks, a discussion about fresh and stored RBC could be clinically relevant [104].

\section{Conclusions and Recommendations}

The evidence supports that each institution establishes its own patient blood management strategy to both conserve blood products and maximise outcome.

Newer transfusion guidelines in patients with coexisting cardiac diseases are similar to those in patients without such comorbidities. Thus, RBC transfusions are most often indicated at haemoglobin levels below $6.0 \mathrm{~g} / \mathrm{dL}(3.7 \mathrm{mmol} / \mathrm{L})$ and hardly ever at haemoglobin levels above $10 \mathrm{~g} / \mathrm{dL}(6.1 \mathrm{mmol} / \mathrm{L})$ [25]. In cardiac surgery, especially in CAD patients, the lower limit should probably be elevated to $7 \mathrm{~g} / \mathrm{dL}(4.3 \mathrm{mmol} / \mathrm{L})$, though no available hard evidence. Institutions should evaluate how they approach transfusion and each physician should evaluate each patient for signs and symptoms of ischemia or imbalance in oxygen supply and delivery, where the major challenge is how to decide when that imbalance is occurring in certain tissues. Evidently such signs may be reached at higher haemoglobin values than in healthy patients, but further studies are needed to fully confirm that transfusing these patients at a higher haemoglobin level positively is making more good than harm.

Following this teams and institutions need to conduct open discussions about how they will approach patient blood management and instead of previous fixed haemoglobin levels the best practice would be individual haemoglobin/haematocrit triggers.

\section{Transfusion Strategy: Issues to Consider When Making a Strategy}

(1) Strategy of transfusion: Make local policy and guidelines for transfusion including

(i) Preferably developing an algorithm for transfusion

(ii) Education and knowledge of physicians and nurses

(iii) Policy on blood saving precautions, mechanical or medical

(iv) Evaluation of cost of blood/blood products and cost alternatives

(v) Availability of blood and blood products (vi) Transfusion of only actual bleeding and/or unstable patients

(vii) Safety related to need

(viii) Affection of immune system acceptable?

(2) Preoperative evaluation

(i) Deciding blood saving precautions

(ii) Cardiovascular reserve

(iii) Defining acceptable blood loss/haematocrit/ absolute haemoglobin content.

(3) Evaluate perioperative

(i) Haematocrit look at it-do not treat it but

(ii) Evaluate the absolute amount of haemoglobin.

(4) Reevaluate cardiovascular capacity and decide transfusion need.

\section{Conflict of Interests}

The author declares that there is no conflict of interests regarding the publication of this paper.

\section{References}

[1] P. C. Hébert, G. Wells, M. A. Blajchman et al., "A multicenter, randomized, controlled clinical trial of transfusion requirements in critical care," The New England Journal of Medicine, vol. 340, no. 6, pp. 409-417, 1999.

[2] S. M. Horwitz, K. Kelleher, P. M. T. Thomas Boyce et al., "Anemia and blood transfusion in critically ill patients," Journal of the American Medical Association, vol. 288, no. 12, pp. 1499-1507, 2002.

[3] J. D. Rawn, "Blood transfusion in cardiac surgery: a silent epidemic revisited," Circulation, vol. 116, no. 22, pp. 2523-2524, 2007.

[4] C. G. Koch, L. Li, A. I. Duncan et al., "Morbidity and mortality risk associated with red blood cell and blood-component transfusion in isolated coronary artery bypass grafting," Critical Care Medicine, vol. 34, no. 6, pp. 1608-1616, 2006.

[5] J. J. Andreasen, C. Dethlefsen, I. S. Modrau et al., "Storage time of allogeneic red blood cells is associated with risk of severe postoperative infection after coronary artery bypass grafting," European Journal of Cardio-thoracic Surgery, vol. 39, no. 3, pp. 329-334, 2011.

[6] G. J. Murphy, B. C. Reeves, C. A. Rogers, S. I. A. Rizvi, L. Culliford, and G. D. Angelini, "Increased mortality, postoperative morbidity, and cost after red blood cell transfusion in patients having cardiac surgery," Circulation, vol. 116, no. 22, pp. 25442552, 2007.

[7] W. M. Weightman, N. M. Gibbs, M. R. Sheminant, M. A. J. Newman, and D. E. Grey, "Moderate exposure to allogeneic blood products is not associated with reduced long-term survival after surgery for coronary artery disease," Anesthesiology, vol. 111, no. 2, pp. 327-333, 2009.

[8] M. C. Engoren, R. H. Habib, A. Zacharias, T. A. Schwann, C. J. Riordan, and S. J. Durham, "Effect of blood transfusion on long-term survival after cardiac operation," Annals of Thoracic Surgery, vol. 74, no. 4, pp. 1180-1186, 2002. 
[9] A. H. M. van Straten, M. W. A. Bekker, M. A. Soliman Hamad et al., "Transfusion of red blood cells: the impact on short-term and long-term survival after coronary artery bypass grafting, a ten-year follow-up," Interactive Cardiovascular and Thoracic Surgery, vol. 10, no. 1, pp. 37-42, 2010.

[10] S. D. Surgenor, R. S. Kramer, E. M. Olmstead et al., "The association of perioperative red blood cell transfusions and decreased long-term survival after cardiac surgery," Anesthesia and Analgesia, vol. 108, no. 6, pp. 1741-1746, 2009.

[11] L. T. Goodnough, M. E. Brecher, M. H. Kanter, and J. P. AuBuchon, "Transfusion medicine-blood transfusion," The New England Journal of Medicine, vol. 340, no. 6, pp. 438-447, 1999.

[12] C. Madjdpour and D. R. Spahn, "Allogeneic red blood cell transfusions: efficacy, risks, alternatives and indications," British Journal of Anaesthesia, vol. 95, no. 1, pp. 33-42, 2005.

[13] E. C. Vamvakas and J. H. Carven, "Allogeneic blood transfusion, hospital charges, and length of hospitalization: A study of 487 consecutive patients undergoing colorectal cancer resection," Archives of Pathology and Laboratory Medicine, vol. 122, no. 2, pp. 145-151, 1998.

[14] G. J. Taylor, F. L. Mikell, H. W. Moses et al., "Determinants of hospital charges for coronary artery bypass surgery: the economic consequences of postoperative complications," The American Journal of Cardiology, vol. 65, no. 5, pp. 309-313, 1990.

[15] L. A. Herwaldt, S. K. Swartzendruber, M. B. Edmond et al., "The epidemiology of hemorrhage related to cardiothoracic operations," Infection Control and Hospital Epidemiology, vol. 19, no. 1, pp. 9-16, 1998.

[16] L. J. Dacey, J. J. Munoz, Y. R. Baribeau et al., "Reexploration for hemorrhage following coronary artery bypass grafting: incidence and risk factors," Archives of Surgery, vol. 133, no. 4, pp. 442-447, 1998.

[17] R. C. Woodman and L. A. Harker, "Bleeding complications associated with cardiopulmonary bypass," Blood, vol. 76, no. 9, pp. 1680-1697, 1990.

[18] G. J. Despotis, K. S. Filos, T. N. Zoys, C. W. Hogue Jr., E. Spitznagel, and D. G. Lappas, "Factors associated with excessive postoperative blood loss and hemostatic transfusion requirements: a multivariate analysis in cardiac surgical patients," Anesthesia and Analgesia, vol. 82, no. 1, pp. 13-21, 1996.

[19] A. S. Kestin, C. R. Valeri, S. F. Khuri et al., "The platelet function defect of cardiopulmonary bypass," Blood, vol. 82, no. 1, pp. 107117, 1993.

[20] M. J. Moulton, L. L. Creswell, M. E. Mackey, J. L. Cox, and M. Rosenbloom, "Reexploration for bleeding is a risk factor for adverse outcomes after cardiac operations," Journal of Thoracic and Cardiovascular Surgery, vol. 111, no. 5, pp. 1037-1046, 1996.

[21] B. D. Spiess, "Transfusion of blood products affects outcome in cardiac surgery," Seminars in Cardiothoracic and Vascular Anesthesia, vol. 8, no. 4, pp. 267-281, 2004.

[22] G. J. Despotis, M. S. Avidan, and C. W. Hogue Jr., "Mechanisms and attenuation of hemostatic activation during extracorporeal circulation," Annals of Thoracic Surgery, vol. 72, no. 5, pp. S1821S1831, 2001.

[23] D. Paparella, S. J. Brister, and M. R. Buchanan, "Coagulation disorders of cardiopulmonary bypass: a review," Intensive Care Medicine, vol. 30, no. 10, pp. 1873-1881, 2004.

[24] C. J. Jakobsen, P. K. Ryhammera, M. Tang, J. J. Andreasen, and P. E. Mortensen, "Transfusion of blood during cardiac surgery is associated with higher long-term mortality in low-risk patients," European Journal of Cardio-Thoracic Surgery, vol. 42, no. 1, pp. 114-120, 2012.

[25] L. C. Stehling, D. C. Doherty, R. J. Faust et al., "Practice guidelines for blood component therapy: a report by the American Society of Anesthesiologists Task Force on Blood Component Therapy," Anesthesiology, vol. 84, no. 3, pp. 732-747, 1996.

[26] C. Jakobsen, "Strategy of transfusion in cardiac surgery: limits of hematocrit and how much is too low?" Future Cardiology, vol. 3, no. 2, pp. 141-151, 2007.

[27] Z. M. Chen and L. X. Jiang, "Addition of clopidogrel to aspirin in 45852 patients with acute myocardial infarction: randomised placebo-controlled trial," The Lancet, vol. 366, no. 9497, pp. 1607-1621, 2005.

[28] S. Yusuf, F. Zhao, S. R. Mehta, S. Chrolavicius, G. Tognoni, and K. K. Fox, "Clopidogrel in unstable angina to prevent recurrent events trial investigators.: effects of clopidogrel in addition to aspirin in patients with acute coronary syndromes without STsegment elevation," The New England Journal of Medicine, vol. 345, pp. 494-502, 2001.

[29] S. R. Mehta, S. Yusuf, R. J. G. Peters et al., "Effects of pretreatment with clopidogrel and aspirin followed by long-term therapy in patients undergoing percutaneous coronary intervention: The PCI-CURE study," The Lancet, vol. 358, no. 9281, pp. 527-533, 2001.

[30] K. A. Bybee, B. D. Powell, U. Valeti et al., "Preoperative aspirin therapy is associated with improved postoperative outcomes in patients undergoing coronary artery bypass grafting," Circulation, vol. 112, no. 9, pp. I286-I292, 2005.

[31] S. R. Steinhubl, P. B. Berger, J. Tift Mann III et al., "Early and sustained dual oral antiplatelet therapy following percutaneous coronary intervention: a randomized controlled trial," Journal of the American Medical Association, vol. 288, no. 19, pp. 24112420, 2002.

[32] S. S. Nijjer, G. Watson, T. Athanasiou, and I. S. Malik, "Safety of clopidogrel being continued until the time of coronary artery bypass grafting in patients with acute coronary syndrome: a meta-analysis of 34 studies," European Heart Journal, vol. 32, no. 23, pp. 2970-2988, 2011.

[33] M. Kremke, M. Tang, K. Lawaetz et al., "Antiplatelet therapy at the time of coronary artery bypass grafting-a multicenter cohort study," European Journal Cardio-Thoracic Surgery, vol. 44, no. 2, pp. e133-e140, 2013.

[34] A. Miceli, S. M. J. Duggan, G. Aresu et al., "Combined clopidogrel and aspirin treatment up to surgery increases the risk of postoperative myocardial infarction, blood loss and reoperation for bleeding in patients undergoing coronary artery bypass grafting," European Journal of Cardio-thoracic Surgery, vol. 43, no. 4, pp. 722-728, 2013.

[35] R. H. Mehta, M. T. Roe, J. Mulgund et al., "Acute clopidogrel use and outcomes in patients with non-ST-segment elevation acute coronary syndromes undergoing coronary artery bypass surgery," Journal of the American College of Cardiology, vol. 48, no. 2, pp. 281-286, 2006.

[36] J. S. Berger, C. B. Frye, Q. Harshaw, F. H. Edwards, S. R. Steinhubl, and R. C. Becker, "Impact of clopidogrel in patients with acute coronary syndromes requiring coronary artery bypass surgery: a multicenter analysis," Journal of the American College of Cardiology, vol. 52, no. 21, pp. 1693-1701, 2008.

[37] K. A. Fox, S. R. Mehta, R. Peters et al., "Clopidogrel in Unstable angina to prevent Recurrent ischemic Events Trial: benefits and risks of the combination of clopidogrel and aspirin in 
patients undergoing surgical revascularization for non-STelevation acute coronary syndrome: the Clopidogrel in Unstable angina to prevent Recurrent ischemic Events (CURE) trial," Circulation, vol. 110, no. 10, pp. 1202-1208, 2004.

[38] C. R. Herman, K. J. Buth, B. A. Kent, and G. M. Hirsch, "Clopidogrel increases blood transfusion and hemorrhagic complications in patients undergoing cardiac surgery," Annals of Thoracic Surgery, vol. 89, no. 2, pp. 397-402, 2010.

[39] D. Fitchett, J. Eikelboom, S. Fremes et al., "Dual antiplatelet therapy in patients requiring urgent coronary artery bypass grafting surgery: a position statement of the Canadian Cardiovascular Society," Canadian Journal of Cardiology, vol. 25, no. 12, pp. 683-689, 2009.

[40] J. Dunning, M. Versteegh, A. Fabbri et al., "Guideline on antiplatelet and anticoagulation management in cardiac surgery," European Journal of Cardio-Thoracic Surgery, vol. 34, no. 1, pp. 73-92, 2008.

[41] J. T. Kuikka and E. Lansimies, "Effect of age on cardiac index, stroke index and left ventricular ejection fraction at rest and during exercise as studied by radiocardiography," Acta Physiologica Scandinavica, vol. 114, no. 3, pp. 339-343, 1982.

[42] M. P. Fillinger, S. D. Surgenor, C. Clark, G. S. Hartman, and W. C. Paganelli, "The impact on mortality of managing hemodilutional anemia with RBC transfusion after CABG," Anesthesiology, vol. 95, pp. 95-A201, 2001.

[43] J. Hardy, R. Martineau, A. Couturier, S. Bélisle, R. Cartier, and M. Carrier, "Influence of haemoglobin concentration after extracorporeal circulation on mortality and morbidity in patients undergoing cardiac surgery," British Journal of Anaesthesia, vol. 81, no. 1, pp. 38-45, 1998.

[44] A. W. Bracey, R. Radovancevic, S. A. Riggs et al., "Lowering the hemoglobin threshold for transfusion in coronary artery bypass procedures: effect on patient outcome," Transfusion, vol. 39, no. 10, pp. 1070-1077, 1999.

[45] P. C. Hébert, E. Yetisir, C. Martin et al., "Is a low transfusion threshold safe in critically ill patients with cardiovascular diseases?" Critical Care Medicine, vol. 29, no. 2, pp. 227-234, 2001.

[46] W. Wu, S. S. Rathore, Y. Wang, M. J. Radford, and H. M. Krumholz, "Blood transfusion in elderly patients with acute myocardial infarction," The New England Journal of Medicine, vol. 345, no. 17, pp. 1230-1236, 2001.

[47] D. Zindrou, K. M. Taylor, and J. P. Bagger, "Preoperative haemoglobin concentration and mortality rate after coronary artery bypass surgery," The Lancet, vol. 359, no. 9319, pp. 1747$1748,2002$.

[48] F. Roques, S. A. M. Nashef, P. Michel et al., "Risk factors and outcome in European cardiac surgery: analysis of the Euro-SCORE multinational database of 19030 patients," European Journal of Cardio-Thoracic Surgery, vol. 15, no. 6, pp. 816-822, 1999.

[49] S. A. M. Nashef, F. Roques, P. Michel, E. Gauducheau, S. Lemeshow, and R. Salamon, "European system for cardiac operative risk evaluation (EuroSCORE)," European Journal of Cardio-Thoracic Surgery, vol. 16, no. 1, pp. 9-13, 1999.

[50] F. Roques, P. Michel, A. R. Goldstone, and S. A. M. Nashef, “The logistic EuroSCORE," European Heart Journal, vol. 24, no. 9, pp. 881-882, 2003.

[51] S. Sinclair, S. James, and M. Singer, "Intraoperative intravascular volume optimisation and length of hospital stay after repair of proximal femoral fracture: randomised controlled trial," British Medical Journal, vol. 315, no. 7113, pp. 909-912, 1997.
[52] T. J. Gan, A. Soppitt, M. Maroof et al., "Goal-directed intraoperative fluid administration reduces length of hospital stay after major surgery," Anesthesiology, vol. 97, no. 4, pp. 820-826, 2002.

[53] K. Reinhart, T. Rudolph, D. L. Bredle, L. Hannemann, and S. M. Cain, "Comparison of central-venous to mixed-venous oxygen saturation during changes in oxygen supply/demand," Chest, vol. 95, no. 6, pp. 1216-1221, 1989.

[54] J. C. Berridge, "Influence of cardiac output on the correlation between mixed venous and central venous oxygen saturation," The British Journal of Anaesthesia, vol. 69, no. 4, pp. 409-410, 1992.

[55] A. Lorentzen, C. Lindskov, E. Sloth, and C. Jakobsen, "Central venous oxygen saturation cannot replace mixed venous saturation in patients undergoing cardiac surgery," Journal of Cardiothoracic and Vascular Anesthesia, vol. 22, no. 6, pp. 853857, 2008.

[56] G. R. DeFoe, C. S. Ross, E. M. Olmstead et al., "Lowest hematocrit on bypass and adverse outcomes associated with coronary artery bypass grafting," Annals of Thoracic Surgery, vol. 71, no. 3, pp. 769-776, 2001.

[57] W. C. Fang, R. E. Helm, K. H. Krieger et al., "Impact of minimum hematocrit during cardiopulmonary bypass on mortality in patients undergoing coronary artery surgery," Circulation, vol. 96, supplement 2, pp. 194-199, 1997.

[58] S. E. Hill, G. K. Van Wermeskerken, J. H. Lardenoye et al., "Intraoperative physiologic variables and outcome in cardiac surgery: part I. In-hospital mortality," Annals of Thoracic Surgery, vol. 69, no. 4, pp. 1070-1076, 2000.

[59] D. R. Spahn, E. R. Schmid, B. Seifert, and T. Pasch, "Hemodilution tolerance in patients with coronary artery disease who are receiving chronic $\beta$-adrenergic blocker therapy," Anesthesia and Analgesia, vol. 82, no. 4, pp. 687-694, 1996.

[60] D. R. Spahn and M. Casutt, "Eliminating blood transfusions: new aspects and perspectives," Anesthesiology, vol. 93, no. 1, pp. 242-255, 2000.

[61] L. Herregods, L. Foubert, A. Moerman, K. Francois, and G. Rolly, "Comparative study of limited intentional normovolaemic haemodilution in patients with left main coronary artery stenosis," Anaesthesia, vol. 50, no. 11, pp. 950-953, 1995.

[62] D. R. Spahn, B. Seifert, T. Pasch, and E. R. Schmid, "Effects of chronic $\beta$-blockade on compensatory mechanisms during acute isovolaemic haemodilution in patients with coronary artery disease," British Journal of Anaesthesia, vol. 78, no. 4, pp. 381385, 1997.

[63] D. R. Spahn, L. R. Smith, R. L. McRae, and B. J. Leone, "Effects of acute isovolemic hemodilution and anesthesia on regional function in left ventricular myocardium with compromised coronary blood flow," Acta Anaesthesiologica Scandinavica, vol. 36, no. 7, pp. 628-636, 1992.

[64] D. R. Spahn, L. R. Smith, C. D. Veronee et al., "Acute isovolemic hemodilution and blood transfusion: effects on regional function and metabolism in myocardium with compromised coronary blood flow," Journal of Thoracic and Cardiovascular Surgery, vol. 105, no. 4, pp. 694-704, 1993.

[65] J. M. Leung, A. Voskanian, W. H. Bellows, and D. Pastor, "Automated electrocardiograph ST segment trending monitors: accuracy in detecting myocardial ischemia," Anesthesia and Analgesia, vol. 87, no. 1, pp. 4-10, 1998.

[66] M. E. Comunale, S. C. Body, C. Ley et al., "The concordance of intraoperative left ventricular wall-motion abnormalities and electrocardiographic S-T segment changes: association with 
outcome after coronary revascularization," Anesthesiology, vol. 88, no. 4, pp. 945-954, 1998.

[67] C. W. Hogue, L. T. Goodnough, and T. G. Monk, "Perioperative myocardial ischemic episodes are related to hematocrit level in patients undergoing radical prostatectomy," Transfusion, vol. 38, no. 10, pp. 924-931, 1998.

[68] J. M. Leung, R. B. Weiskopf, J. Feiner et al., "Electrocardiographic ST-segment changes during acute, severe isovolemic hemodilution in humans," Anesthesiology, vol. 93, no. 4, pp. 1004-1010, 2000.

[69] J. L. Carson, H. Noveck, J. A. Berlin, and S. A. Gould, "Mortality and morbidity in patients with very low postoperative Hb levels who decline blood transfusion.", Transfusion, vol. 42, no. 7, pp. 812-818, 2002.

[70] M. Casutt, B. Seifert, T. Pasch, E. R. Schmid, M. I. Turina, and D. R. Spahn, "Factors influencing the individual effects of blood transfusions on oxygen delivery and oxygen consumption," Critical Care Medicine, vol. 27, no. 10, pp. 2194-2200, 1999.

[71] D. R. Spahn, A. Zollinger, R. B. Schlumpf et al., "Hemodilution tolerance in elderly patients without known cardiac disease," Anesthesia and Analgesia, vol. 82, no. 4, pp. 681-686, 1996.

[72] D. R. Spahn, N. Dettori, R. Kocian, and P. Chassot, "Transfusion in the cardiac patient," Critical Care Clinics, vol. 20, no. 2, pp. 269-279, 2004.

[73] D. R. Spahn, B. Seifert, T. Pasch, and E. R. Schmid, "Haemodilution tolerance in patients with mitral regurgitation," Anaesthesia, vol. 53, no. 1, pp. 20-24, 1998.

[74] A. Zollinger, P. Hager, T. Singer, H. P. Friedl, T. Pasch, and D. R. Spahn, "Extreme hemodilution due to massive blood loss in tumor surgery," Anesthesiology, vol. 87, no. 4, pp. 985-987, 1997.

[75] P. S. Levy, S. J. Kim, P. K. Eckel et al., "Limit to cardiac compensation during acute isovolemic hemodilution: influence of coronary stenosis," American Journal of Physiology: Heart and Circulatory Physiology, vol. 265, no. 1, pp. H340-H349, 1993.

[76] D. R. Spahn, L. R. Smith, R. M. Schell, R. D. Hoffman, R. Gillespie, and B. J. Leone, "Importance of severity of coronary artery disease for the tolerance to normovolemic hemodilution: comparison of single-vessel versus multivessel stenoses in a canine model," Journal of Thoracic and Cardiovascular Surgery, vol. 108, no. 2, pp. 231-239, 1994.

[77] S. Slogoff and A. S. Keats, "Does perioperative myocardial ischemia lead to postoperative myocardial infarction," Anesthesiology, vol. 62, no. 2, pp. 107-114, 1985.

[78] D. L. Reich, C. A. Bodian, M. Krol, M. Kuroda, T. Osinski, and D. M. Thys, "Intraoperative hemodynamic predictors of mortality, stroke, and myocardial infarction after coronary artery bypass surgery," Anesthesia \& Analgesia, vol. 89, no. 4, pp. 814822, 1999.

[79] D. L. Reich, E. Bennett-Guerrero, C. A. Bodian, S. Hossain, W. Winfree, and M. Krol, "Intraoperative tachycardia and hypertension are independently associated with adverse outcome in noncardiac surgery of long duration," Anesthesia and Analgesia, vol. 95, no. 2, pp. 273-277, 2002.

[80] K. E. Raby, S. J. Brull, F. Timimi et al., "The effect of heart rate control on myocardial ischemia among high-risk patients after vascular surgery," Anesthesia and Analgesia, vol. 88, no. 3, pp. 477-482, 1999.

[81] T. L. Simon, D. C. Alverson, J. AuBuchon et al., "Practice parameter for the use of red blood cell transfusions: developed by the Red Blood Cell Administration Practice Guideline Development Task Force of the College of American pathologists,"
Archives of Pathology and Laboratory Medicine, vol. 122, no. 2, pp. 130-138, 1998.

[82] D. R. Spahn, U. Schanz, and T. Pasch, "Perioperative transfusionskriterien," Anaesthesist, vol. 47, pp. 1011-1020, 1998.

[83] M. J. London, M. Hollenberg, M. G. Wong et al., "Intraoperative myocardial ischemia: localization by continuous 12-lead electrocardiography," Anesthesiology, vol. 69, no. 2, pp. 232-241, 1988.

[84] Z. Bak, L. Abildgård, B. Lisander, and B. Janerot-Sjöberg, "Transesophageal echocardiographic hemodynamic monitoring during preoperative acute normovolemic hemodilution," Anesthesiology, vol. 92, no. 5, pp. 1250-1256, 2000.

[85] D. R. Spahn, K. F. Waschke, T. Standl et al., "Use of perflubron emulsion to decrease allogeneic blood transfusion in highblood-loss non-cardiac surgery: results of a European phase 3 study," Anesthesiology, vol. 97, no. 6, pp. 1338-1349, 2002.

[86] D. K. Wilkerson, A. L. Rosen, S. A. Gould, L. R. Sehgal, H. L. Sehgal, and G. S. Moss, "Oxygen extraction ratio: a valid indicator of myocardial metabolism in anemia," Journal of Surgical Research, vol. 42, no. 6, pp. 629-634, 1987.

[87] G. S. Moss, R. DeWoskin, A. L. Rosen, H. Levine, and C. K. Palani, "Transport of oxygen and carbon dioxide by hemoglobin saline solution in the red cell free primate," Surgery Gynecology and Obstetrics, vol. 142, no. 3, pp. 357-362, 1976.

[88] A. Trouwborst, R. Tenbrinck, and E. C. van Woerkens, "Blood gas analysis of mixed venous blood during normoxic acute isovolemic hemodilution in pigs," Anesthesia \& Analgesia, vol. 70, no. 5, pp. 523-529, 1990.

[89] D. R. Spahn, B. J. Leone, J. G. Reves, and T. Pasch, "Cardiovascular and coronary physiology of acute isovolemic hemodilution: a review of nonoxygen-carrying and oxygen-carrying solutions," Anesthesia and Analgesia, vol. 78, no. 5, pp. 1000$1021,1994$.

[90] R. B. Weiskopf, M. K. Viele, J. Feiner et al., "Human cardiovascular and metabolic response to acute, severe isovolemic anemia," Journal of the American Medical Association, vol. 279, no. 3, pp. 217-221, 1998.

[91] E. Sloth, C. Lindskov, A. G. Lorentzen, M. Nygaard, H. H. Kure, and C.-J. Jakobsen, "Cardiac surgery patients present considerable variation in pre-operative hemodynamic variables," Acta Anaesthesiologica Scandinavica, vol. 52, no. 7, pp. 952-958, 2008.

[92] C. E. Stevens, R. D. Aach, F. B. Hollinger et al., "Hepatitis B virus antibody in blood donors and the occurrence of non$\mathrm{A}$, non-B hepatitis in transfusion recipients: an analysis of the transfusion-transmitted viruses study," Annals of Internal Medicine, vol. 101, no. 6, pp. 733-738, 1984.

[93] P. E. Marik and W. J. Sibbald, "Effect of stored-blood transfusion on oxygen delivery in patients with sepsis," Journal of the American Medical Association, vol. 269, no. 23, pp. 3024-3029, 1993.

[94] J. Ho, W. J. Sibbald, and I. H. Chin-Yee, "Effects of storage on efficacy of red cell transfusion: when is it not safe?" Critical Care Medicine, vol. 31, no. 12, pp. S687-S697, 2003.

[95] A. Tinmouth and I. Chin-Yee, "The clinical consequences of the red cell storage lesion," Transfusion Medicine Reviews, vol. 15, no. 2, pp. 91-107, 2001.

[96] F. R. Purdy, M. G. Tweeddale, and P. M. Merrick, "Association of mortality with age of blood transfused in septic ICU patients," Canadian Journal of Anaesthesia, vol. 44, no. 12, pp. 1256-1261, 1997. 
[97] G. Zallen, P. J. Offner, E. E. Moore et al., "Age of transfused blood is an independent risk factor for postinjury multiple organ failure," The American Journal of Surgery, vol. 178, no. 6, pp. 570-572, 1999.

[98] R. D. Fitzgerald, C. M. Martin, G. E. Dietz, G. S. Doig, R. F. Potter, and W. J. Sibbald, "Transfusing red blood cells stored in citrate phosphate dextrose adenine-1 for 28 days fails to improve tissue oxygenation in rats," Critical Care Medicine, vol. 25, no. 5, pp. 726-732, 1997.

[99] J. van Bommel, D. de Korte, A. Lind et al., "The effect of the transfusion of stored RBCs on intestinal microvascular oxygenation in the rat," Transfusion, vol. 41, no. 12, pp. 1515-1523, 2001.

[100] A. G. Tsai, P. Cabrales, and M. Intaglietta, "Microvascular perfusion upon exchange transfusion with stored red blood cells in normovolemic anemic conditions," Transfusion, vol. 44, no. 11, pp. 1626-1634, 2004.

[101] N. J. Raat, A. J. Verhoeven, E. G. Mik et al., "The effect of storage time of human red cells on intestinal microcirculatory oxygenation in a rat isovolemic exchange model," Critical Care Medicine, vol. 33, no. 1, pp. 39-45, 2005.

[102] T. S. Walsh, F. McArdle, S. A. McLellan et al., "Does the storage time of transfused red blood cells influence regional or global indexes of tissue oxygenation in anemic critically ill patients?" Critical Care Medicine, vol. 32, no. 2, pp. 364-371, 2004.

[103] H. L. Corwin, A. Gettinger, R. G. Pearl et al., "The CRIT Study: anemia and blood transfusion in the critically ill-current clinical practice in the United States," Critical Care Medicine, vol. 32, no. 1, pp. 39-52, 2004.

[104] N. J. H. Raat, F. Berends, A. J. Verhoeven, D. de Korte, and C. Ince, "The age of stored red blood cell concentrates at the time of transfusion," Transfusion Medicine, vol. 15, no. 5, pp. 419-423, 2005. 


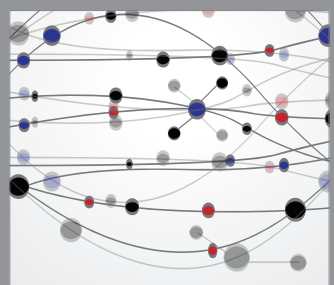

The Scientific World Journal
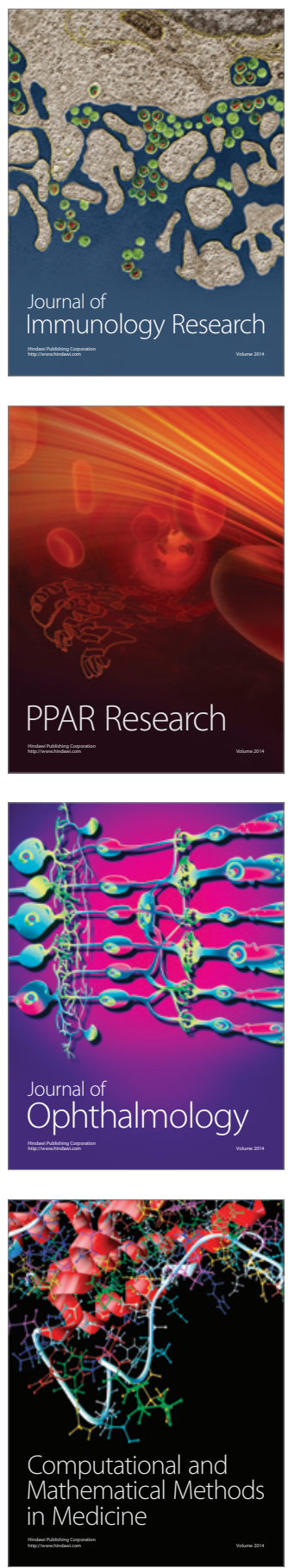

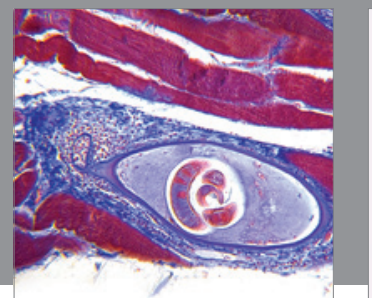

Gastroenterology

Research and Practice
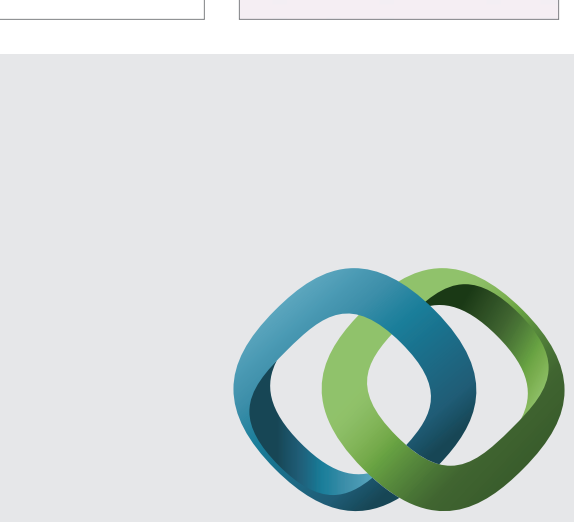

\section{Hindawi}

Submit your manuscripts at

http://www.hindawi.com
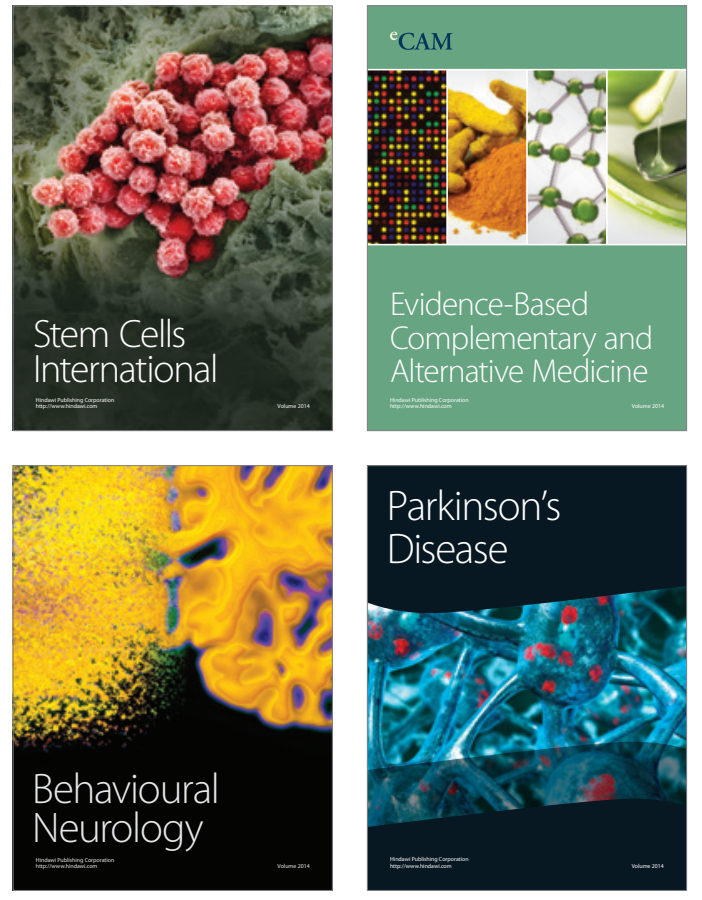
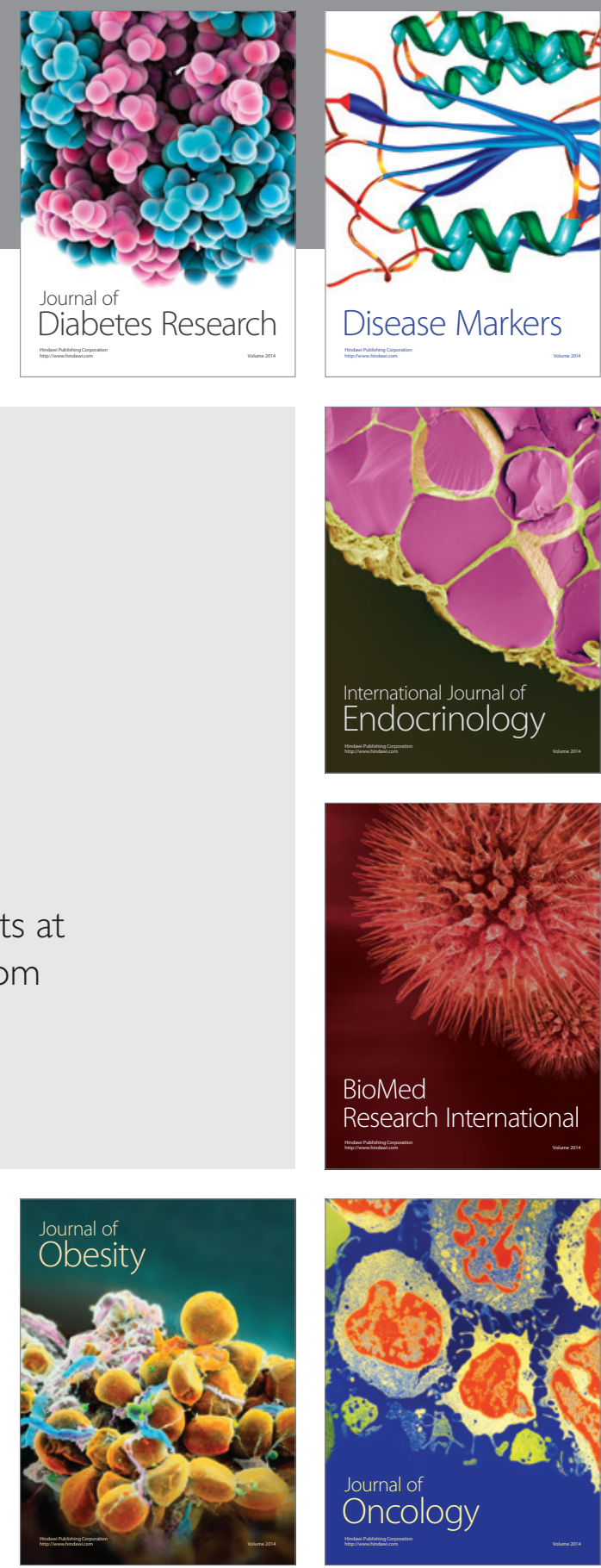

Disease Markers
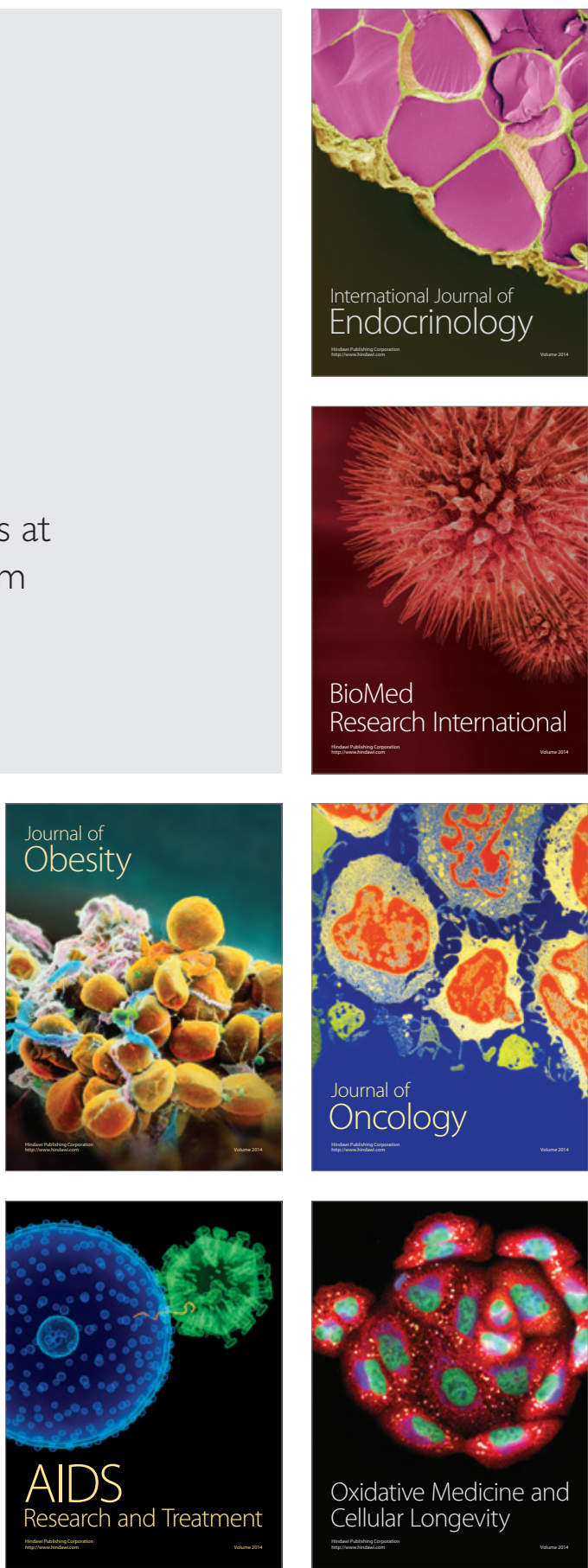